\title{
Article \\ Smart Data-Driven Policy on Unmanned Aircraft Systems (UAS): Analysis of Drone Users in U.S. Cities
}

\author{
Yu-Che Chen ${ }^{1, *}$ and Chenyu Huang ${ }^{2}$ (I) \\ 1 Digital Governance and Analytics Lab and School of Public Administration, University of Nebraska at \\ Omaha, CPACS 111, 6001 Dodge Street, Omaha, NE 68182, USA \\ 2 Aviation Institute, School of Public Administration, College of Public Affairs and Community Service, \\ University of Nebraska at Omaha, CPACS 111, 6001 Dodge Street, Omaha, NE 68182, USA; \\ chenyuhuang@unomaha.edu \\ * Correspondence: ychen@unomaha.edu
}

check for updates

Citation: Chen, Y.-C.; Huang, C. Smart Data-Driven Policy on Unmanned Aircraft Systems (UAS): Analysis of Drone Users in U.S. Cities. Smart Cities 2021, 4, 78-92. https:// doi.org/10.3390/smartcities4010005

Received: 13 December 2020 Accepted: 31 December 2020 Published: 7 January 2021

Publisher's Note: MDPI stays neutral with regard to jurisdictional clai$\mathrm{ms}$ in published maps and institutional affiliations.

Copyright: $\odot 2021$ by the authors. Licensee MDPI, Basel, Switzerland. This article is an open access article distributed under the terms and conditions of the Creative Commons Attribution (CC BY) license (https:// creativecommons.org/licenses/by/ $4.0 /)$.

\begin{abstract}
Realizing the benefits of drones while minimizing public concerns requires development and implementation of drone use policies that are grounded in an understanding of drone users and their behavior. This study aims to contribute to data-driven smart cities by filling our gap in knowledge about city drone users and their compliance behavior. The literature review has identified the main factors affecting drone policy compliance. This study collects data via a national survey of adults on drone behavior and focuses on city drone users. The results show that city drone users are younger with more dispersed educational backgrounds and income distribution than those in the general population. Moreover, civic duty, trust in government, and knowledge about regulatory requirements are motivators for drone users to comply with drone regulation.
\end{abstract}

Keywords: smart cities; unmanned aircraft systems (UAS); drones; regulation; policy; compliance

\section{Introduction}

Smart cities use technological solutions to improve the management and efficiency of the urban environment at reduced cost [1]. Policy is an integral aspect of smart cities [2], and the pursuit of smart city performance involves the development of supportive policy and institutions $[3,4]$. With the continuing advances and innovations in a variety of emerging technologies—such as 5G networks, robotics, internet of things, and artificial intelligence-smart city design and operations were offered diverse intelligent solutions to manage city resources and services to residents. The unmanned aircraft system (UAS) is an example of those emerging technologies that are being integrated into smart cities for various advantages $[5,6]$. More importantly, safe and effective use of emerging UAS technology not only expands the scope of intelligent devices in a smart city environment, but also provides innovative solutions to overcoming limitations imposed by existing city infrastructure.

As a flexible and aerial mobile platform, UAS could be used in many fields in smart city operations, for instance, traffic management, infrastructure inspection, parcel delivery, and public safety. With the capabilities of fast deployment and real-time image data collection, UAS is considered a useful tool in traffic monitoring and management, and numerous cases have been studied and tested to support smart city traffic management using UAS [7-9]. Smart city infrastructure inspection can also benefit from the UAS technology given its lowcost operations and rapid data collection [10]. Examples of utilizing UAS for infrastructure inspection include road and bridges [11], power lines [12], and buildings [13]. Parcel delivery is another example of UAS application in smart cities [14]. Amazon Prime Air, DHL, UPS, and many other express companies have been actively facilitating commercial operations of drone delivery from different perspectives. 
Despite potential advantages, the use of UAS raises public policy concerns. Safety, security, and privacy are three of the most common concerns for the use of drones $[15,16]$. Safety and security are usually considered as technical issues, and because of the operational and environmental characteristics of flying drones in smart cities, high safety requirements for drone operations (such as proximity, speed, altitude, and maneuverability) must be developed, evaluated, and tested-particularly in urban settings [6]. Privacy concerns are usually discussed as non-technical issues and addressed from regulatory standpoints. Privacy concerns could arise from drone pilots' misbehavior in collecting images and video of people or private property or the potential leak of personal data. For smart cities, safety, privacy and ethical uses are the main concerns for UAS applications [5,14].

In the United States, the Federal Aviation Administration (FAA) leads the effort to develop and implement UAS polices. It has regulations on the registration of UAS, flight altitude, fly-over restrictions, drone pilot behavior, prohibition of interference with emergency response activity, permitting, and operation in appropriate airspace. In addition, the U.S. Department of Transportation assists in integrating UAS into the transportation regulatory framework. It selected ten smart city authorities and regional government agencies to explore the implications of integrating UAS into the national airspace [17]. The policy implementation challenge lies in the enforcement of these regulations at the local level, given no staffing of local enforcement officers for these regulations.

The gap in our knowledge about drone users also presents an opportunity for research into drone user attitudes and behavior for data-driven policy development and implementation. There are systematic research works on the concerns of the public and experts on drone uses $[18,19]$. However, little is known about drone users' attitudes and behavior with regards to compliance with UAS regulations at the local level. Such knowledge is crucial for designing and implementing compliance strategies. It is particularly beneficial for the development and implementation of UAS policy and rules to leverage the benefits of UAS for smart cities while addressing safety and privacy concerns.

This article aims to fill our knowledge gap in drone users' policy compliance for data-driven UAS applications for smart cities. The next section begins with information and literature on characteristics of drone users and factors affecting their regulatory compliance. A section with research data and methods for an empirical investigation into these characteristics and factors follows. The next section presents the findings of this study on the demographics of drone users and factors affecting their compliance. Then, these findings and their implications are discussed. This article concludes with a summary of the main points and opportunities for further research.

\section{Characteristics of Drone Users and Factors for Drone Regulatory Compliance}

\subsection{Characteristics of Drone Users}

According to the FAA, there were an estimated 2 million drones in use in the United States by the end of 2019 [20]. In the same document, the FAA estimated that 1.3 of the 2 million drones (65\%) are for recreational use with close to 1 million of those registered. The projected annual growth rate of drones in the US is approximately $6.4 \%$, and the number of recreational drones in the US is forecast to reach around 1.5 million drones at its peak.

Although the FAA does not collect demographic information (beyond legally requiring an owner's address, e-mail, and model) as part of registration requirements, a survey conducted by a private entity in 2020 suggests that $15 \%$ of Americans have flown a drone. In terms of drone ownership, the 35-54 age group led at $42 \%$ and was followed by the $18-34$ age group at $36 \%$ [21].

Approximately one-third of U.S. adults have drone experience, according to a national survey conducted by the authors. This national survey is representative of U.S. census data on adult education, income, and age groups and included 1260 responses. These drone users are relatively younger than the U.S. adult population in general, based on the 2019 U.S. Census data. Approximately $70 \%$ of the adult drone users are below the age of 44 as 
opposed to the $46 \%$ that comprises this group in the general U.S. adult population. The distribution of education levels among drone users is comparable with such distribution among U.S. adults. Drone users tend to be slightly more concentrated in both the lower and higher income brackets than is the case for the U.S. general adult population. The highest percentage of drone users ( $24 \%$ ) belong to the $\$ 25 \mathrm{~K}$ to $\$ 50 \mathrm{~K}$ category. Nineteen percent of drone users belong to the $\$ 0 \mathrm{~K}$ to $25 \mathrm{~K}$ category, and $15 \%$ are in the $\$ 150 \mathrm{~K}$ and above category.

\subsection{Factors for Drone Regulation Compliance: A Literature Review}

For regulatory compliance, a sense of civic duty can serve as a motivation [17,22,23]. The role of civic duty has an independent and significant impact on regulatory compliance among other motivations for compliance such as fear of punishment [24]. For compliance with drone regulations, drone users are likely to draw on their motivation to contribute to socially responsible use of drones. Public safety is one of the main issues facing drone use $[16,19]$. A sense of duty to promote safe use of drones can serve as a motivation for drone users to comply with drone use policies for safety. Similarly, since an invasion of individual privacy by drones taking pictures or video footage is another concern of the public [19], drone users can be motivated by a sense of duty to protect other people's privacy by following government drone-use regulations.

However, individual drone users also have concerns about compliance with drone use policies. The FAA requires small drone users to register their drones if the weight of the drone is between 0.55 and 55 pounds [25]. Commercial drone registration requires individuals to provide their names, mailing addresses, e-mails, and models of their drones. Drone users could have a concern about their personal and drone-use data being shared or leaked, which could infringe on their individual privacy. Moreover, the emerging nature of drone regulations could also raise concerns among drone users with regard to being targeted for regulatory enforcement when their addresses and drone models are known to the regulator. At the same time, it should be noted that the concern could be mitigated by the lack of enforcement by FAA. FAA does not have the enforcement staff to enforce drone safety regulations. It relies on local governments for enforcing drone safety rules in a city.

Societal trust in drone technologies is requisite for realizing the potential benefits of drone uses $[18,19,26]$. It is crucial for society to have confidence that drones will not compromise safety and security and will not be misused by the government or individuals. To address trust concerns from the community in government use of drones, the U.S. Department of Justice supported the development and publication of Guidelines to Enhance Community Trust [4]. Moreover, a growing number of government agencies, especially law enforcement, have started using drones, and more states in the United States have published local drone laws to regulate drone use to be accountable to the general public.

Such societal trust is inclusive of trust in government along with products, technology, and companies [18]. Public trust in government's fair and effective implementation of drone regulations is likely to be an important factor for successful drone regulation implementation. An effective regulatory strategy needs to include fostering trust in government in addition to incentives and enforcement [27]. Trust in government can translate into compliance [28] and encourages individuals to follow government regulations. Empirical evidence suggests a correlation between level of trust in government and that of individual compliance [21,29]. Such trust in government among drone users is likely to be translated into drone policy compliance.

Knowledge plays an important role in citizens' acceptance of drones in public life. An increase in public knowledge about drones may likely change people's position toward drone applications in the community. Therefore, industry communication and media coverage might influence the ultimate positions adopted by the public [30]. Exploration of public acceptance of drones suggests that the public is not aware of most of the future drone applications nor many current applications, and does not have a high rate of acceptance for drone use at present except for public safety and scientific research applications [31]. 
Knowledge about regulation is likely to form the foundation for regulatory compliance [32]. Unlike taxes and traffic laws, regulatory requirements for emerging technologies may not be common knowledge. As a result, drone users may be in non-compliance because of their lack of knowledge about regulatory requirements for operating drones. Information about drones in the public sphere typically comes from mainstream news media, movies, and TV series [31]. In mass media, the specific requirements for drone regulations and compliance are usually not the emphasis. As a result, current and potential drone users do not have the benefit of mass media coverage to learn about the applicable drone regulations and their requirements.

Training and outreach can play important roles in bridging the knowledge gap about the specifics of drone regulations and actions required for compliance. Currently, drone users are required to pass an aeronautical knowledge test for commercial UAS operation license [25]. Potential commercial UAS users could get training from a variety of avenues, such as institutions, aviation training agencies, clubs, online resources, or self-study. To be licensed as commercial UAS operators, participants are expected to have a professional knowledge and practice of UAS-related regulations and codes of conduct. Therefore, UAS training is one of the essential approaches to ensure the safe use and integration of UAS into other sectors in the smart city environment.

Despite the FAA's current work developing an aeronautical knowledge test that will be mandatory for recreational drone users, the present laws do not require recreational drone users to acquire formal training or pass a knowledge test. Outreach and informal training have been practiced in many disciplines to engage targeted group with resources, information, or services, and with the goal of ultimately changing behaviors. Aviation and STEM education are two example areas in which outreach programs are widely implemented [33]; recreational drone users present a novel group that could benefit from well-tailored outreach programs. Participation in drone-related club activities is one of the forums for drone users to share information and get training. Drone clubs in high schools and colleges or in local communities could serve such a role. Support to these club activities and provision of training could further the goal of ensuring safe operation of the drones and avoidance of any intrusion into people's privacy.

The perceived legitimacy of the governmental body can shape the level of compliance by the general public [26,34]. For perceived legitimacy, context matters [34,35]. In the case of drone regulations, efforts have been made by federal, state, and local governments to address issues of safety and privacy. The U. S. Department of Justice supported the development and publication of guidelines for implementation at the local level [4]. The Federal Aviation Administration (FAA) published a fact sheet providing examples of UAS laws likely to fall within state and local government authorities [36]. As of 2019, 18 states have published state laws to further regulate drone operations-in addition to the federal level drone regulations [37]. These drone-related state laws cover certain restrictions that are also included in the federal drone regulations. For example, Arkansas prohibits drones flying over property, including correctional and other facilities for utilities, defense, telecommunications, and railroads [37]. In addition, many states formed UAS task forces to monitor, regulate, and report drone operations to improve the regulation of drones, such as the Joint State Government Commission on UAS in Pennsylvania and the Advisory Group on UAS in Ohio [38,39]. The perceived legitimacy of the main government body (either federal, state, or local) is likely to influence drone users' compliance behavior.

The purposes of drone use are likely to matter in regulatory compliance. Currently, different federal laws are regulating the use of drones based on purpose. The FAA published Part 107 under the Title 14 Code of Federal Regulations for commercial use of small UAS in 2016, which requires drone owners to obtain a remote pilot certificate to operate small UAS for commercial purposes by passing an aeronautical knowledge test or completing online training [25]. Although a new rule was introduced by the FAA's Reauthorization Bill to require knowledge and safety test for recreational drone users, no remote pilot certificate or qualification test is currently required for recreational drone users [25]. The current UAS 
regulatory requirements result in different mastery and practice of aeronautical knowledge between recreational drone users and commercial drone users. It is important to understand those who operate drones for recreational purposes because they constitute approximately $70 \%$ of the registered drone use. More importantly, easy access to drone technology and the lack of a knowledge test requirement may make regulatory compliance challenging among recreational drone users regardless of their intention to comply with relevant rules.

\section{Research Data and Methods}

This study is based on a national survey of U.S. adults to understand the profile of drone users and their compliance behavior. The random sample aimed to be representative of the demographics of the U.S. adult population in income, age, and education. The research team worked with Qualtrics to gain access to its large and verified panel of respondents in the United States. In addition, quality assurance measures secured each respondent's commitment, unique IP address, validation, force-response, and time-tocompletion. At the same time, the survey platform provided customization especially for mobile devices to improve usability and the quality of presentation. The questionnaire was in the field from 11 to 17 March 2020.

For the focus on smart cities, analysis was performed on the 370 drone users who live in a city. These drone user responses come from the survey conducted by the researchers with a national sample of 1206 responses across all states in the U.S, among which 458 respondents (around $38 \%$ of the adult population of the U.S.) have drone-related experience. Among these 458 respondents, 370 of them live in a big city, a suburb in a metropolitan area, or a small town. In addition, this study incorporates the information from a master list of states that have promulgated their own state-specific regulations [37]. The goal is to see whether such state-specific regulations impact drone users' compliance with federal (FAA) regulations.

The survey questions build from the literature review on factors affecting drone user behavior and are specific and relevant to drones and the FAA regulation on drone registration. The motivation question asks the respondent to rate on the scale of 1 to 5 whether the improvement of public safety is the reason for their drone registration. The concerns question asks (a) whether the leak of personal data is the biggest barrier and (b) whether the fear of more regulation is the biggest barrier to be in compliance with the FAA.

The question about trust in government asks the respondents about the extent to which they can trust government to do what is right. Since the regulation comes from the U.S. FAA, the question is specific to federal government. A related question is asked about who should set the rules for drones. The respondent can indicate whether federal government should set the rules as opposed to state and local governments as an indication of the perceived legitimacy of FAA.

The question on knowledge asks whether a respondent knows that drones that weigh between 0.55 pounds $(250 \mathrm{~g})$ and 55 pounds $(25 \mathrm{~kg})$ are required to be registered according to the FAA rules. The training question asks how often the respondent participates in drone-related training on a scale of 1 to 5 , where 5 is very often and 1 is never. In addition to knowledge and training, a survey question asks respondents about their participation in drone-related club activities on the frequency scale of 1 to 5 , where 5 is "very often" and 1 is "never." Such activities could assist with the dissemination of drone-related knowledge and training.

The intent to register (the dependent variable) is on a seven-point scale of a respondent's willingness to comply with current FAA regulations on drone registration where "1" means "not at all" willing and "7" means "very willing." The question specifically indicates the information required for drone registration ("name, address, e-mail, phone, type and number of drones") as well as the current lack of enforcement.

The demographic questions follow typical census categories for education and income. The education question asks about the highest level of school that a respondent has com- 
pleted or the highest degree a respondent has received? $(1=$ High school incomplete or less, 2 = High school graduate or GED, 3 = Some college, $4=$ Four-year college degree $/$ bachelor's degree, 5 = Some postgraduate or professional schooling, no postgraduate degree, $6=$ Postgraduate or professional degree, including master's, doctorate, medical or law degree). The income question asks specifically about the family income from the last year (2019) from all sources, before taxes $(1=\$ 0-<\$ 25 \mathrm{~K}, 2=\$ 25 \mathrm{~K}-<\$ 50 \mathrm{~K}, 3=\$ 50 \mathrm{~K}-<\$ 7 \mathrm{~K}, 4=\$ 75 \mathrm{k}-100 \mathrm{~K}$, $5=\$ 100 \mathrm{~K}-<\$ 150 \mathrm{~K}, 6=\$ 150 \mathrm{~K}-<\$ 200 \mathrm{~K}, 7=\$ 200 \mathrm{~K}+)$. A question on gender allows respondents to indicate their gender (female or male). The information on the age of the respondent is captured as the actual age and then grouped into age groups typically used by the U.S. Census for reporting purposes.

This study conducted descriptive analysis of city drone users to understand their demographic profiles with the goal to provide data for policy development and implementation. Moreover, this study utilized multiple regression to explore various factors that affect compliance with drone regulations. Multiple regression allows for statistical control to assess the independent impact of each factor in the context of considering all factors, including demographics. Data analysis included a check on multi-collinearity where all the VIFs are below 2; no serious concerns about multi-collinearity were registered because all of them are well below the value of 10, a threshold value for serious multicollinearity issues [40].

\section{City Drone Users: Findings on Demographics and Compliance with Drone Regulations}

\subsection{Demographics}

The results of descriptive analysis of city drone users are summarized in Table 1 . The majority of these drone users $(67 \%)$ are below the age of 44 . Half of these drone users are below the age of 35 (median). The drone users who are 65 or older constitute about $6 \%$ of the total drone users. In terms of education, high school graduate or GED is the largest group $(31.6 \%$ ) for drone use, followed by a community college associate's degree at $21.2 \%$. Eighty percent of the city drone users fall within the first four levels of education, ranging from high school or less to four-year college degree/bachelor's degree. Approximately $40 \%$ of the drone users have family incomes of $\$ 50,000$ or less.

Table 1. Demographics of drone users vs. U.S. adult population.

\begin{tabular}{|c|c|c|c|}
\hline & Category & $\begin{array}{l}\% \text { of Drone Users } \\
\text { in Cities }(n=370)\end{array}$ & $\begin{array}{l}\% \text { of U.S. Adult } \\
\text { Population }\end{array}$ \\
\hline \multirow[t]{10}{*}{ Age } & $18-24$ & $20.8 \%$ & $12.8 \%$ \\
\hline & $25-34$ & $25.3 \%$ & $17.7 \%$ \\
\hline & $35-44$ & $22.9 \%$ & $16.7 \%$ \\
\hline & $45-54$ & $15.9 \%$ & $17.7 \%$ \\
\hline & $55-64$ & $8.6 \%$ & $16.4 \%$ \\
\hline & $65+$ & $6.2 \%$ & $18.8 \%$ \\
\hline & Mean & 37.8 & \\
\hline & Median & 35 & \\
\hline & Highest & 81 & \\
\hline & Lowest & 18 & \\
\hline \multirow[t]{6}{*}{ Education } & High school or less & $13.2 \%$ & $13 \%$ \\
\hline & High school graduate or GED & $31.6 \%$ & $28 \%$ \\
\hline & Community college, associate's degree & $21.2 \%$ & $21 \%$ \\
\hline & $\begin{array}{l}\text { Four-year college } \\
\text { degree/bachelor's degree }\end{array}$ & $15.9 \%$ & $19 \%$ \\
\hline & $\begin{array}{l}\text { Some postgraduate or professional } \\
\text { schooling, no postgraduate degree }\end{array}$ & $2.4 \%$ & \\
\hline & $\begin{array}{c}\text { Master's, doctorate, medical or } \\
\text { law degree }\end{array}$ & $15.7 \%$ & $11 \%$ \\
\hline
\end{tabular}


Table 1. Cont.

\begin{tabular}{cccc}
\hline Category & $\begin{array}{r}\text { \% of Drone Users } \\
\text { in Cities }(\mathbf{n}=370)\end{array}$ & $\begin{array}{c}\text { \% of U.S. Adult } \\
\text { Population }\end{array}$ \\
\hline Income & $\$ 0-<\$ 25 \mathrm{~K}$ & $18.6 \%$ & $18 \%$ \\
& $\$ 25 \mathrm{~K}-<\$ 50 \mathrm{~K}$ & $21.9 \%$ & $22 \%$ \\
$\$ 50 \mathrm{~K}-<\$ 75 \mathrm{~K}$ & $11.6 \%$ & $19 \%$ \\
$\$ 75 \mathrm{k}-<\$ 100 \mathrm{~K}$ & $14.1 \%$ & $14 \%$ \\
$\$ 100 \mathrm{~K}-<\$ 150 \mathrm{~K}$ & $17.3 \%$ & $15 \%$ \\
& $\$ 150 \mathrm{~K}-<\$ 200 \mathrm{~K}$ & $8.4 \%$ & $6 \%$ \\
$\$ 200 \mathrm{~K}+$ & $8.1 \%$ & $6 \%$ \\
\hline
\end{tabular}

The comparison between the demographics of city drone users and those of the U.S. adult population based on U.S. Census data (as shown in Table 1) indicates several key patterns. First, city drone users are younger than the U.S. adult population. This discrepancy is particularly pronounced in the 18-24 age group, where the percentage of city drone users is $20.8-10 \%$ more than that of U.S. adult population. For the $25-34$ age group, $25 \%$ of city drone users are in this group compared to $17.7 \%$ of the U.S. adult population. The difference is greatest in the $65+$ age group, where only $6.2 \%$ of city drone users belong to this age group in comparison with $18.8 \%$ in the U.S. general adult population.

For education, city drone users have comparable percentages in various levels of education as those of U.S. general population. For high school graduate or GED, the percentage of city drone users in this category is slightly higher (approximately $4 \%$ more) than that of U.S. adult population. For the four-year college/bachelor's degree, the percentage of city drone users is less than that of U.S. general population. For income, city drone users have more percentage of them in the higher household income brackets than that of U.S. general population. It should be noted that this difference is only several percentage points, as seen in the $\$ 100 \mathrm{~K}-<\$ 150 \mathrm{~K}, \$ 150 \mathrm{~K}-<\$ 200 \mathrm{~K}$, and $\$ 200 \mathrm{~K}+$.

The results of the comparison between the demographics of drone users living in a metropolitan area and those of drone users living in a small city are in Table 2. Drone users living in a small city appear to be younger than those living in a metropolitan area, judged by average and median ages. Sixty percent of the drone users living in a small city are 34 or younger. That is $6 \%$ more than the percentage of drone users who are 34 or younger and living a metropolitan area. The percentage of small city drone users who have high school graduate or GED or less is at 56 . That is greater than $40 \%$ of the metropolitan drone users who belong to the same educational level. As a percent, more of the small city drone users belong to the lower educational attainment categories. The comparison between the percentage of small city drone users and that of metropolitan drone users exhibit a similar pattern. More than $62 \%$ of the small city drone users have household income of $\$ 50 \mathrm{~K}$ or less. That is greater than $36 \%$ of the metropolitan drone users who have household income of $\$ 50 \mathrm{~K}$ or less.

Table 2. Drone users in metropolitan areas vs. in small cities.

\begin{tabular}{|c|c|c|c|}
\hline & Category & $\begin{array}{c}\% \text { of Drone Users from } \\
\text { Metropolitan Areas }(n=265)\end{array}$ & $\begin{array}{l}\% \text { of Drone Users from } \\
\text { Small Cities }(n=105)\end{array}$ \\
\hline \multirow[t]{10}{*}{ Age } & $18-24$ & $17.7 \%$ & $28.6 \%$ \\
\hline & $25-34$ & $23.4 \%$ & $30.5 \%$ \\
\hline & $35-44$ & $23.4 \%$ & $21.9 \%$ \\
\hline & $45-54$ & $18.5 \%$ & $9.5 \%$ \\
\hline & $55-64$ & $9.5 \%$ & $6.6 \%$ \\
\hline & $65+$ & $7.5 \%$ & $2.9 \%$ \\
\hline & Mean & 39.5 & 33.5 \\
\hline & Median & 38 & 31 \\
\hline & Highest & 81 & 73 \\
\hline & Lowest & 18 & 18 \\
\hline
\end{tabular}


Table 2. Cont.

\begin{tabular}{|c|c|c|c|}
\hline & Category & $\begin{array}{c}\text { \% of Drone Users from } \\
\text { Metropolitan Areas }(n=265)\end{array}$ & $\begin{array}{l}\text { \% of Drone Users from } \\
\text { Small Cities }(n=105)\end{array}$ \\
\hline \multirow[t]{6}{*}{ Education } & High school or less & $11.3 \%$ & $18.1 \%$ \\
\hline & High school graduate or GED & $29.1 \%$ & $38.1 \%$ \\
\hline & Community college, associate's degree & $20.8 \%$ & $21.9 \%$ \\
\hline & Four-year college degree/bachelor's degree & $18.1 \%$ & $10.5 \%$ \\
\hline & $\begin{array}{l}\text { Some postgraduate or professional schooling, no } \\
\text { postgraduate degree }\end{array}$ & $3.0 \%$ & $0.9 \%$ \\
\hline & Master's, doctorate, medical or law degree & $17.7 \%$ & $10.5 \%$ \\
\hline \multirow[t]{7}{*}{ Income } & $\$ 0-<\$ 25 \mathrm{~K}$ & $15.5 \%$ & $26.7 \%$ \\
\hline & $\$ 25 \mathrm{~K}-<\$ 50 \mathrm{~K}$ & $20.4 \%$ & $25.7 \%$ \\
\hline & $\$ 50 \mathrm{~K}-<\$ 75 \mathrm{~K}$ & $10.9 \%$ & $13.3 \%$ \\
\hline & $\$ 75 \mathrm{k}-<\$ 100 \mathrm{~K}$ & $15.8 \%$ & $9.5 \%$ \\
\hline & $\$ 100 \mathrm{~K}-<\$ 150 \mathrm{~K}$ & $18.5 \%$ & $14.3 \%$ \\
\hline & $\$ 150 \mathrm{~K}-<\$ 200 \mathrm{~K}$ & $9.1 \%$ & $6.7 \%$ \\
\hline & $\$ 200 \mathrm{~K}+$ & $9.8 \%$ & $3.8 \%$ \\
\hline
\end{tabular}

\subsection{Drone User Compliance with Drone Regulations}

The results of city drone user compliance with drone regulations are summarized in Table 3. The focus is on drone users' willingness to comply with the drone registration regulations set by the U.S. Federal Aviation Administration (FAA). The overall model is statistically significant with an adjusted R-square of 0.306 . The results provide empirical data for assessing the statements made in the literature review section. The concern about leak of personal data (e.g., address, e-mail, drone info) does not register a statistically significant relationship with willingness to comply, controlling for other factors identified by the literature. Neither does concern about further regulation register a statistically significant relationship.

Table 3. Individual drone regulatory compliance: Intent of compliance with drone registration regulation.

\begin{tabular}{|c|c|}
\hline Variables & Unstandardized Beta \\
\hline Concern about leak of personal data & -0.125 \\
\hline Concern about further regulation & -0.005 \\
\hline Civic duty to public safety & $0.496^{* * *}$ \\
\hline Trust in government & $0.402^{* * *}$ \\
\hline Federal government as a rule-setter & 0.291 \\
\hline Existence of state regulation & -0.079 \\
\hline Knowledge about drone registration requirement & 0.446 * \\
\hline Participation in drone-related training & 0.028 \\
\hline Drone use (commercial and recreational) & $-0.514 *$ \\
\hline Participation in drone-related club activities & -0.174 \\
\hline Education & -0.025 \\
\hline Income & 0.067 \\
\hline Gender & 0.088 \\
\hline \multicolumn{2}{|l|}{ Model Summary } \\
\hline Number of observations in the model & 337 \\
\hline Adjusted R-Square & 0.306 \\
\hline
\end{tabular}

The civic duty to public safety as a motivation for drone regulation compliance has a statistically positive significant relationship with city drone users' willingness to comply. This is controlling for all other factors potentially affecting regulatory compliance behavior and at the 0.001 level of significance. City drone users' trust in federal government also has a statistically significant relationship with their willingness to comply. Controlling for all other variables in the model, trust in government is statistically significant at the 
0.001 level. Next, city drone users' opinions on whether federal government should set drone regulations does not have a statistically significant relationship with their willingness to comply. The existence of state legislation for states that responding city drone users reside in does not bear a statistically significant relationship with the users' willingness to comply.

A city drone user's knowledge about the drone registration requirement, controlling for all other factors, does register a positive and statistically significant relationship with the user's willingness to be in compliance. Participation in drone-related training by a city drone user does not have a statistically significant relationship with the user's willingness to comply.

City drone users who use drones for both commercial and recreational purposes are less willing to comply with the FAA registration requirement in comparison with those drone users who use drones for a single purpose (either commercial or recreational). This relationship is statistically significant, controlling for all other factors. City drone users participation in drone-related club activities does not register a statistically significant relationship with their willingness to comply.

Education level of the city drone users does not have a statistically significant relationship with their willingness to comply, controlling for all the other factors in the model. Income level of the city drone users does not register a statistically significant relationship with their willingness to comply. Neither gender of the city drone users has registered any statistically significant relationship with their willingness to comply.

\section{Discussions and Implications for Data-Driven Drone Regulations}

\subsection{Demographic Characteristics of Drone Users for Data-Driven Smart City Policies}

As reported in the findings and summarized in Table 1, city drone users are younger than those in the general adult population. Forty-six percent of these drone users are below the age of 35 as opposed to $30 \%$ in the general population. A data-driven smart city manager focusing on drone uses could apply this information to devise a campaign for regulatory compliance by targeting younger demographics. Such efforts could involve the use of social networking platforms that are preferred by the younger demographic and messaging that resonates better with them. The data also shows that drone use is less pervasive in those who are 55 or older with this demographic accounting for only $15 \%$ of drone users in comparison with $35 \%$ in the general adult population. If the goal is to launch a more targeted educational campaign, it should aim for the preferences of younger demographics to increase impact. Considering younger adults might be less concerned with drone regulations, individual privacy, and public safety, much more effort could be needed to address safety and privacy concerns about drones especially in an urban setting.

For education, more of the city drone users are in the "high school graduate or GED" group and the "Master's, doctorate, medical or law degree" groups than those in the general adult population. An effective strategy to reach out to city drone users needs to take into account this trend. One way to address this issue is to tailor mass media deployment and prepared content to reach these two distinctive groups. With regard to income, city drone users cluster more in the three income brackets over $\$ 100 \mathrm{~K}$ $(\$ 100 \mathrm{~K}-<\$ 150 \mathrm{~K}, \$ 150 \mathrm{~K}-<200 \mathrm{~K}$, and $\$ 200 \mathrm{~K}$ plus) than the U.S. adult population in general. A more targeted strategy to educate people about regulatory requirements for safe operation of drones can take advantage of this data to formulate messages that resonate better with people in these income brackets. At the same time, it is important to implement effective practices for reaching out to city drone users who belong to income brackets of $\$ 0-<\$ 25 \mathrm{~K}$ and $\$ 25 \mathrm{~K}-<\$ 50 \mathrm{~K}$. The percentages of city drone users in these income groups are comparable with those of the general adult populations in the U.S.

The differences in demographics (as shown in Table 2) warrant distinctive strategies for drone users in metropolitan areas (big cities and suburbs) as opposed to those in small cities. Drone users in a small city are younger than their counterparts in metropolitan areas. For the age group of $18-24$, there is $10 \%$ difference between drone users in a small city 
$(28.6 \%)$ and drone users in a metropolitan area (17.7\%). The percentage of the $18-24$ age group for small city drone users (almost three in every ten) implies the effectiveness of a more targeted effort reaching out to this particular demographic. Having about $60 \%$ of drone users in a small city in the 18-24 and 25-34 age groups further reinforces the idea of focusing on younger demographics in a small city.

There are markedly higher percentages of small city drone users who belong to "high school or less" and "high school graduate or GED" than those of drone users in a metropolitan area. Over $50 \%$ of drone users in small cities have an education level that is in either one of these categories, as opposed to less than $40 \%$ of drone users in the same categories in a metropolitan area. Awareness of this difference could assist drone safety policy makers in designing and implementing measures that match the levels of the respective demographics. For instance, the educational material should target the corresponding reading level. Any outreach via media should also cater to the demographics in a small city rather than applying the same thinking for drone users in metropolitan areas. For income, a higher percentage (approximately 52\%) of drone users in a small city belong to the $\$ 0 \mathrm{~K}-\$ 50 \mathrm{~K}$ than that (approximately $36 \%$ ) of drone users in a metropolitan area. A compliance strategy at the local level should take into account this discrepancy to devise incentives accordingly. For example, financial incentives may have more of an impact in a small city as opposed to a metropolitan area.

In the model of regulatory compliance as summarized in Table 3, none of the demographics (education, income, gender) registers a statistically significant relationship with willingness to comply when all other factors are controlled for. These findings suggest that the education level of city drone users would not impact their compliance. It could be that the knowledge and skills needed for flying drones are easy to acquire and are not associated with educational degrees. It is also plausible that formal education does not have an impact on city drone users' attitude either. The affordability of small drones and minimal cost of compliance could be the reasons for not seeing a relationship between income and compliance. For the consumer-grade small UAS, regardless of whether for recreational or commercial purposes, the general public could access one because of the affordable price range. Considering the registration requirement by the FAA, the cost of regulatory compliance is minimal; compliance is more about following rules than incurring the cost. Next, gender does not play a role in regulatory compliance. This finding is not surprising given that the existing literature has not suggested any role played by gender.

For smart city policy makers regulating drones, the findings on demographics based on a regression model suggest a more inclusive strategy that takes into account drone users with all educational and income levels. Such inclusiveness for promoting compliance should appeal to a cross-section of the adult population rather than focusing on one particular demographic. Moreover, more attention should be given to other factors that have registered a significant impact on regulatory compliance.

\subsection{Factors for Regulatory Compliance for City Drone Users}

Neither the concern about leak of personal data nor the concern about further regulation has registered as a factor for willingness to comply with FAA drone registration regulations despite empirical support in the literature for such concern as expressed by citizens [19]. One plausible explanation for the lack of concerns is the limited capability of FAA in enforcing these drone regulations. Further regulations would not be a source of concern when they are not enforced. Privacy concern can be mitigated by personal data safeguards such as the European Union's General Data Protection Regulation (GDPR). The purpose limitation and confidentiality principles of the GDPR can be applied to limit the collection and leak of personal information connected to drone use. Moreover, these concerns are less prominent when a set of factors such as a sense of civic duty and knowledge about the regulation are considered for regulatory compliance in the model. The policy implication for drone regulators focusing on city drone uses is to cast an important qualifier for policy recommendations based on these concerns. A data-driven smart city 
effort focusing on drones could be less concerned about these two potential barriers to compliance.

The civic duty to the protection of public safety is an important factor in determining city drone users' willingness to comply. The statistical significance of this relationship underscores the confidence that such a relationship could exist among city drone users in general. This finding confirms the importance of civic duty in individual compliance with mandatory regulation $[23,41]$. The relevance of a sense of civic duty as a motivator for individuals advances our understanding of individual compliance with government regulations for emerging technologies. For policy makers, the implication is that appealing to an individual's sense of civic duty to produce compliance with drone regulations can be effective. A smart regulation could offer recognition or reward to incentivize individuals to be in compliance.

Among many factors for regulatory compliance, city drone users' trust in federal government bears an independent and statistically significance relationship with the willingness to comply with FAA drone registration regulations. The finding suggests that the importance of trust in government extends beyond tax regulation [27] to drone regulations. This suggests to regulators the importance of engendering citizens' trust in government as a positive factor to inducing compliance behavior. It also suggests the challenge of ensuring compliance when the overall level of trust in government is low [29]. For policy makers at the FAA, fostering trust in government in general and trust in the FAA in particular is likely to produce a high level of compliance. At the local level, the broader effort to increase trust in government is likely to yield compliance for drone regulation.

City drone users' opinions on whether federal government should set the drone regulations as opposed to other levels of government does not have a statistically significant relationship with their willingness to comply. It is plausible that city drone users could take the role of the FAA as a federal government agency as given. Therefore, it does not become a factor in determining their willingness to comply. Similarly, the existence of state regulations as an indicator of government drone regulations and activity at the lower level of government does not register a significant relationship with city drone users' willingness to comply. It is likely that city drone users may not be aware of these state-level regulatory activities or knowledge about such regulation not directly impacting their behavior. When faced with declining trust in government, smart city policies on drone safety need to consider other factors for compliance such as tapping into a sense of civic duty or developing targeted campaign focusing on a particular demographic. These measures are under the direct influence of smart city policy makers.

The finding about knowledge supports a positive relationship between city drone users' knowledge about the specific drone regulation requirements and their willingness to comply. For regulatory compliance in general, it supports the important and positive role that knowledge about regulation has in regulatory compliance [22]. For drone regulations, it underscores the importance of imparting the knowledge to drone users. The current portrait of drones is mostly in news media, movies, and TV series-and centers on their use or misuse [31]. For smart city policy makers to ensure safe drone uses, making public service announcements on drone regulation requirements and finding ways to support similar efforts among drone users would be more targeted. However, participation in drone-related training does not translate into willingness to comply among city drone users. It could be that the training is more related to the technical aspect of piloting a drone and less to do with compliance with regulation. Another plausible reason is that most people who participate in drone training already have knowledge about regulation. The effect of such knowledge has been captured in the knowledge factor.

For city drone users, dual-purpose drone use (commercial and recreational) as opposed to single-purpose drone use (commercial or recreational) is negatively associated with their willingness to comply with FAA drone registration regulation. It could be that these dual-purpose drone users find the regulations particularly burdensome and worry that registration could lead to more intrusion/regulation on how they fly their drones. These are 
the users who have to comply with regulations for commercial drone pilots as well as the set of rules for recreational use. For policy makers to ensure compliance, this finding suggests the importance of looking at the burden that regulations have placed on individuals and how such a burden could impact their willingness to comply. This issue is particularly salient when enforcement is limited or non-existence. In that situation, the willingness of drone users, rather than government regulatory enforcement, is likely to determine the level of compliance among drone users.

City drone users' participation in drone club activity does not bear a statistically significant relationship with their willingness to comply with registration regulations. It could be that these drone club activities are more about social activity than about ensuring compliance with government regulation. Moreover, participants probably have basic knowledge about drone regulation. Therefore, participation in club activity is not related to compliance. In addition, their compliance with drone regulation is driven by their civic duty to public safety. Therefore, participation in club activities in the context of other explanations for compliance (e.g., civic duty, trust in government, knowledge) does not impact compliance. For policy makers, this finding cautions against major investment in supporting drone clubs as a means to boost compliance. It is more productive to focus on efforts that leverage civic duty, trust in government, and knowledge about regulations to ensure compliance.

\section{Conclusions}

The goal of this study is to generate knowledge about city drone users for smart city policy makers and managers to devise data-driven regulatory practices to realize the benefits of drones while minimizing their negative impacts. Such knowledge fills an important gap in the understanding of individual drone users' compliance behavior, which is essential for beneficial use of drones in our society with protection of safety and individual privacy. More specifically, this study aims to understand the demographics of city drone users for a focus on smart cities, while distinguishing between drone users living in a metropolitan area and those living in a small city. Moreover, the study develops an exploratory model of the various factors affecting drone regulation compliance by drawing from the literature on smart cities, drones, and regulatory compliance. These include concerns such as leak of personal data and further regulation as barriers to compliance; civic duty as incentives for compliance; trust in government; legitimacy of regulators; knowledge about drone regulations; participation in drone training; drone use; and demographics.

This study focuses on the drone users in U.S. cities based on a national representative survey of the U.S. adult population conducted by the authors. Descriptive statistics, as reported in Table 1, provide a detailed look at the breakdown of demographics of these city drone users compared with the general adult population in the U.S. Table 2 provides a comparison between city drone users in a metropolitan area vs. those in a small city. Table 3 summarizes the regression results of various factors as identified in the literature that could impact compliance with drone regulations.

The findings on demographics suggest that city drone users are younger, more in both the lower and higher educational attainment groups, and more in high income brackets than the general adult population. Such findings imply the need for a strategy customized to these demographic characteristics such as using the more popular social media platforms and communication channels for these segments of the population. Moreover, drone users in a small city are younger, more in the "high school graduate" or "high school or less" categories, and more in the lower income brackets than those in the general population. These findings call for a strategy that is distinctive for small city drone users as opposed to metropolitan drone users. Interestingly, when focusing on regulatory compliance and taking all other factors into account, age, education, and income do not appear as statistically significant factors. Such a finding implies that, for the matter of regulatory compliance, other factors are more salient than demographics. 
The regression results suggest the importance of civic duty and trust in government as motivators for compliance with drone regulations. As a result, a more effective strategy for regulatory compliance could appeal to individuals' sense of civic duty. At the same time, government, as the regulator, should invest in engendering citizens' trust in government for the purpose of their compliance with drone regulation. Knowledge about the drone regulatory requirements is helpful for regulatory compliance. Such findings can be coupled with the data on the demographics of city drone users to develop a targeted educational campaign. The city drone users that use drones for both commercial and recreational purposes would need careful attention because of their unwillingness to comply with drone regulations. It could be that drone regulations are considered as particularly burdensome for dual-use city drone users.

This exploratory study suggests several opportunities for future research to further advance our knowledge about city drone users and their regulatory compliance behavior as well as various applications of UAS for smart cities. One avenue is to conduct indepth studies of drone users in a small city in comparison with those in a metropolitan area in order to generate data and models that reflect the distinctive demographics and potentially compliance behavior. Another avenue is to explore effective means to impart city drone users with knowledge about regulatory requirements since the knowledge itself helps with compliance. Research can gather more information on effective communication platforms or venues for dissemination of knowledge about regulatory requirements. In addition, a comparative study of drone uses in different countries would further shed lights on city drone user characteristics and the factors affecting their compliance with drone regulations. Such a research avenue is particularly productive in exploring the role of national regulations and citizenry in drone uses in a smart city context. As employed by city governments, various innovative applications of UAS for smart city services such as traffic management, infrastructure inspection, parcel delivery, and public safety constitute another important area of further research.

Author Contributions: Conceptualization, Y.-C.C. and C.H.; Methodology, Y.-C.C. and C.H.; Formal Analysis, Y.-C.C. and C.H.; Investigation, Y.-C.C. and C.H.; Writing-Original Draft Preparation, Y.-C.C.; Writing-Review \& Editing, Y.-C.C. and C.H.; Project Administration, C.H.; Funding Acquisition, C.H. All authors have read and agreed to the published version of the manuscript.

Funding: This research was funded by the College of Public Affairs and Community Service at the University of Nebraska at Omaha under the grant of 2019-2020 Inquiry Awards.

Conflicts of Interest: The authors declare no conflict of interest.

\section{References}

1. European Commission. Smart Cities. Available online: https://ec.europa.eu/info/eu-regional-and-urban-development/topics/ cities-and-urban-development/city-initiatives/smart-cities_en (accessed on 13 December 2020).

2. Nam, T.; Pardo, T. Smart City as Urban Innovation: Focusing on Management, Policy, and Context. In Proceedings of the ICEGOV, Tallinn, Estonia, 26-28 September 2011.

3. Meijer, A. Datapolis: A Public Governance Perspective on "Smart Cities". Perspect. Public Manag. Gov. 2018, 1, 195-206. [CrossRef]

4. Valdovinos, M.; Specht, J.; Zeunik, J. Law Enforcement \& Unmanned Aircraft Systems (UAS): Guidelines to Enhance Community Trust; Office of Community Oriented Policing Services: Washington, DC, USA, 2016; Available online: https:/ / www.policefoundation. org/wp-content/uploads/2016/11/UAS-Report.pdf (accessed on 10 December 2020).

5. Khan, M.; Alvi, B.; Safi, E.; Khan, I. Drones for Good in Smart Cities: A Review. In Proceedings of the International Conference on Electrical, Electronics, Computers, Communication, Mechanical and Computing (EECCMC), Vaniyambadi, India, 28-29 January 2018.

6. Mohamed, N.; Al-Jaroodi, J.; Jawhar, I.; Idries, A.; Mohammed, F. Unmanned aerial vehicles applications in future smart cities. Technol. Forecast. Soc. Chang. 2020, 153, 119293. [CrossRef]

7. Barmpounakis, E.; Geroliminis, N. On the new era of urban traffic monitoring with massive drone data: The pNEUMA large-scale field experiment. Transp. Res. Part C Emerg. Technol. 2020, 111, 50-71. [CrossRef]

8. Barmpounakis, E.N.; Vlahogianni, E.I.; Golias, J.C. Unmanned Aerial Aircraft Systems for transportation engineering: Current practice and future challenges. Int. J. Transp. Sci. Technol. 2016, 5, 111-122. [CrossRef]

9. Kanistras, K.; Martins, G.; Rutherford, M.J.; Valavanis, K.P. A Survey of Unmanned Aerial Vehicles (UAVs) for Traffic Monitoring. In Handbook of Unmanned Aerial Vehicles; Springer: Dordrecht, The Netherlands, 2015; pp. 2643-2666. 
10. Mota, R.L.; Felizardo, L.F.; Shiguemori, E.H.; Ramos, A.B.; Mora-Camino, F. Expanding small UAV capabilities with ANN: A case study for urban areas observation. In Proceedings of the 2013 IEEE Second International Conference on Image Information Processing (ICIIP-2013), Shimla, India, 9-11 December 2013.

11. Seo, J.; Duque, L.; Wacker, J.P. Field Application of UAS-Based Bridge Inspection. Transp. Res. Rec. 2018, 2672, 72-81. [CrossRef]

12. Zhang, Y.; Yuan, X.; Li, W.; Chen, S. Automatic Power Line Inspection Using UAV Images. Remote Sens. 2017, 9, 824. [CrossRef]

13. Rakha, T.; Gorodetsky, A. Review of Unmanned Aerial System (UAS) applications in the built environment: Towards automated building inspection procedures using drones. Autom. Constr. 2018, 93, 252-264. [CrossRef]

14. Mohammed, F.; Idries, A.; Mohamed, N.; Al-Jaroodi, J.; Jawhar, I. UAVs for smart cities: Opportunities and challenges. In Proceedings of the 2014 International Conference on Unmanned Aircraft Systems (ICUAS), Orlando, FL, USA, 27-30 May 2014

15. Chamata, J. Factors Delaying the Adoption of Civil Drones: A Primitive Framework. Int. Technol. Manag. Rev. 2017, 6, 125-132. [CrossRef]

16. Nakamura, H.; Kajikawa, Y. Regulation and innovation: How should small unmanned aerial vehicles be regulated? Technol. Forecast. Soc. Chang. 2018, 128, 262-274. [CrossRef]

17. U.S. Department of Transportation. Unmanned Aircraft Systems Integration Pilot Program Selectees. 2020. Available online: https:/ / www.transportation.gov/connections / unmanned-aircraft-systems-integration-pilot-program-selectees-0 (accessed on 10 December 2020).

18. Fox, S.J. The 'risk' of disruptive technology today (A case study of aviation-Enter the drone). Technol. Soc. 2020, 62, 101304. [CrossRef]

19. Nelson, J.; Gorichanaz, T. Trust as an ethical value in emerging technology governance: The case of drone regulation. Technol. Soc. 2019, 59, 101131. [CrossRef]

20. The Federal Aviation Administration. FAA Aerospace Forecasts 2020-2040. 2020. Available online: https://www.faa.gov/data research/aviation/aerospace_forecasts/media/Unmanned_Aircraft_Systems.pdf (accessed on 10 December 2020).

21. Satell, M. Ultimate List of Drone Stats for 2020. Available online: https://www.phillybyair.com/blog/drone-stats/ (accessed on 10 December 2020).

22. May, P.J. Regulation and compliance motivations: Examining different approaches. Public Adm. Rev. 2005, 65, 31-44. [CrossRef]

23. McGraw, K.M.; Scholz, J.T. Appeals to Civic Virtue versus Attention to Self-Interest: Effects on Tax Compliance. Law Soc. Rev. 1991, 25, 471-498. [CrossRef]

24. Scholz, J.T.; Pinney, N. Duty, Fear, and Tax Compliance: The Heuristic Basis of Citizenship Behavior. Am. J. Polit. Sci. 1995, 39, 490-512. [CrossRef]

25. The Federal Aviation Administration. Unmanned Aircraft System (UAS). 2020. Available online: https://www.faa.gov/uas/ (accessed on 10 December 2020).

26. Tyler, T.R. Why People Obey the Law; Yale University Press: New Haven, CT, USA, 1990.

27. Murphy, K. The Role of Trust in Nurturing Compliance: A Study of Accused Tax Avoiders. Law Hum. Behav. 2004, 28, 187-209. [CrossRef] [PubMed]

28. Braithwaite, J.; Makkai, T. Trust and Compliance. Polic. Soc. 1994, 4, 1-12. [CrossRef]

29. Im, T.; Cho, W.; Porumbescu, G.; Park, J. Internet, Trust in Government, and Citizen Compliance. J. Public Adm. Res. Theory 2014, 24, 741-763. [CrossRef]

30. Clothier, R.A.; Greer, D.A.; Greer, D.G.; Mehta, A.M. Risk Perception and the Public Acceptance of Drones. Risk Anal. 2015, 35, 1167-1183. [CrossRef]

31. Aydin, B. Public acceptance of drones: Knowledge, attitudes, and practice. Technol. Soc. 2019, 59, 101180. [CrossRef]

32. May, P.J. Compliance Motivations: Affirmative and Negative Bases. Law Soc. Rev. 2004, 38, 41-68. [CrossRef]

33. Lutte, R.K.; Huang, C. Aviation Outreach: Reaching the Next Generation of Aviation Professionals. In Engaging the Next Generation of Aviation Professionals; Kearns, S.K., Mavin, T., Hodge, S., Eds.; Routledge: New York, NY, USA, 2020; pp. 24-35. ISBN 978-036-725-427-8.

34. Hertogh, M. What moves Joe Driver? How perceptions of legitimacy shape regulatory compliance among Dutch traffic offenders. Int. J. Law Crime Justice 2015, 43, 214-234. [CrossRef]

35. Beetham, D. The Legitimation of Power; Palgrave Macmillan: New York, NY, USA, 1991.

36. The Federal Aviation Administration (FAA). State and Local Regulation of Unmanned Aircraft Systems Fact Sheet; FAA: Washington, DC, USA, 2015.

37. National Conference of State Legislatures. Current Unmanned Aircraft State Law Landscape. Available online: https: / www. ncsl.org/meetings-training/ncsl-meetings-calendar.aspx (accessed on 10 December 2020).

38. DeWine, M. Ohio Attorney General Mike DeWine's Advisory Group on Unmanned Aircraft Systems. 2018. Available online: https: / / www.ohioattorneygeneral.gov / Files/Publications-Files/Publications-for-Law-Enforcement/Advisory-Groupon-Unmanned-Aircraft-Systems-Final (accessed on 10 December 2020).

39. Joint State Government Commission. Joint State Government Commission-Unmanned Aircraft Systems in Pennsylvania. 2017. Available online: http:/ /jsg.legis.state.pa.us/resources/documents/ftp/publications/2017-01-27\%20WEBSITE\%20PDF\%20 UAS\%20(DRONES)\%201.27.17\%20at\%20250\%20WB.pdf (accessed on 10 December 2020). 
40. Gujarati, D.N.; Porter, D.C. Basic Econometrics, 5th ed.; McGraw-Hill/Irwin: Boston, MA, USA, 2009.

41. Winter, S.C.; May, P.J. Motivation for Compliance with Environmental Regulations. J. Policy Anal. Manag. 2001, 20, 675-698. [CrossRef] 